\title{
Effective Henry’s Law Constants of Glyoxal, Glyoxylic Acid, and Glycolic Acid
}

${ }^{1}$ Department of Chemistry, ${ }^{2}$ Atmospheric, Marine and Coastal Environment Program, Hong

4 Kong University of Science \& Technology, Clear Water Bay, Kowloon, Hong Kong, China *Corresponding author phone: 852-2358-7389; fax: 852-2358-1594; email: chjianyu@ust.hk

\section{Abstract}

8 The Henry's law constants of glyoxal, glycolic acid and glyoxylic acid in pure water were determined over the range of 278 and $308 \mathrm{~K}$ for the first time by a bubble column

10 technique. These compounds were chosen because of their perceived involvement in the formation of secondary organic aerosol through in-cloud processing pathways. The 12 experimentally determined Henry's law constants are: glyoxal, $K_{\mathrm{H}}=$ $4.19 \times 10^{5} \times \exp \left[\left(62.2 \times 10^{3} / \mathrm{R}\right) \times(1 / \mathrm{T}-1 / 298)\right] ; \quad$ glycolic $\quad$ acid, $\quad K_{\mathrm{H}}=$

$142.83 \times 10^{4} \times \exp \left[\left(33.5 \times 10^{3} / \mathrm{R}\right) \times(1 / \mathrm{T}-1 / 298)\right] ; \quad$ and glyoxylic acid, $K_{\mathrm{H}}=$ $1.09 \times 10^{4} \times \exp \left[\left(40.0 \times 10^{3} / \mathrm{R}\right) \times(1 / \mathrm{T}-1 / 298)\right]$. The Henry's law constants of glyoxal in the

16 presence of sodium chloride and sodium sulfate were also determined at $298 \mathrm{~K}$. While the glyoxal $K_{\mathrm{H}}$ is enhanced by less than three times in the presence of chloride in the range of 18 0.05-4.0 $\mathrm{M}$ ionic strength, the presence of sulfate at $0.03 \mathrm{M}$ ionic strength increases the glyoxal $K_{\mathrm{H}}$ by 50 times. 


\section{Introduction}

The Henry's law constant, $K_{\mathrm{H}}$, is a key parameter in estimating the magnitude, rate, and direction of the flux of solutes between gas and aqueous phases [Betterton, 1992]. Recent research has revealed that a number of $\mathrm{C}_{2}$ bifunctional compounds (i.e., glycolaldehyde,

24 glyoxal, glyoxylic acid and glycolic acid) are precursors in the aqueous-phase formation of oxalic acid [Blando and Turpin, 2000; Warneck, 2003]. Oxalic acid is the single most

26 abundant water-soluble organic compound that has been identified in ambient aerosols and in-cloud processing is its dominant formation pathway [Sorooshian et al., 2006; Yu et al., 2005]. The $C_{2}$ bifunctional compounds, especially glyoxal, have numerous volatile organic compound (VOC) precursors and are relatively abundant in the atmosphere. Typical ambient

30 gas-phase concentrations of glyoxal range from $20 \mathrm{pptv}\left(\sim 40 \mathrm{ng} \mathrm{m}^{-3}\right)$ in rural environments to $2.0 \mathrm{ppbv}\left(\sim 4.0 \mu \mathrm{g} \mathrm{m}^{-3}\right)$ in urban environments [e.g., Munger et al., 1995; Ho and Yu, 2002;

32 Volkamer et al., 2005]. The ambient abundance of the other three $\mathrm{C}_{2}$ bifunctional compounds was less frequently measured. The cloud-processing of glycolaldehyde and glyoxal, which

34 are formed mainly in the gas phase, is a potentially important pathway leading to formation of secondary organic aerosols (SOA). The evaluation of this pathway requires the knowledge

36 of the Henry's law constants of these compounds and their intermediate aqueous-phase oxidation products (i.e., glycolic acid and glyoxylic acid).

Of the four $\mathrm{C}_{2}$ bifunctional compounds, glycolaldehyde was measured to have a $K_{\mathrm{H}}$ value of $4.14 \times 10^{4} \mathrm{M} \mathrm{atm}^{-1}$ at $298 \mathrm{~K}$ and $1.56 \times 10^{4} \mathrm{M} \mathrm{atm}^{-1}$ at $318 \mathrm{~K}$ [Betterton and Hoffmann,

40 1988]. Two studies in the literature reported $K_{\mathrm{H}}$ measurements of glyoxal; one study provided a lower limit estimate of $3 \times 10^{5} \mathrm{M} \mathrm{atm}^{-1}$ [Betterton and Hoffmann, 1988] and the second study

42 reported a value of $3.6 \times 10^{5} \mathrm{M} \mathrm{atm}^{-1}$ in $100 \%$ seawater, based on only two measurements [Zhou and Mopper, 1990]. The $K_{\mathrm{H}}$ values of glycolic acid and glyoxylic acid have not been 44 measured experimentally.

Both glyoxal and glyoxylic acid undergo hydration in water (see reactions (R1) and 
46 (R2) below). Glyoxylic acid and glycolic acid also undergo acid dissociation (Reaction (R2)).

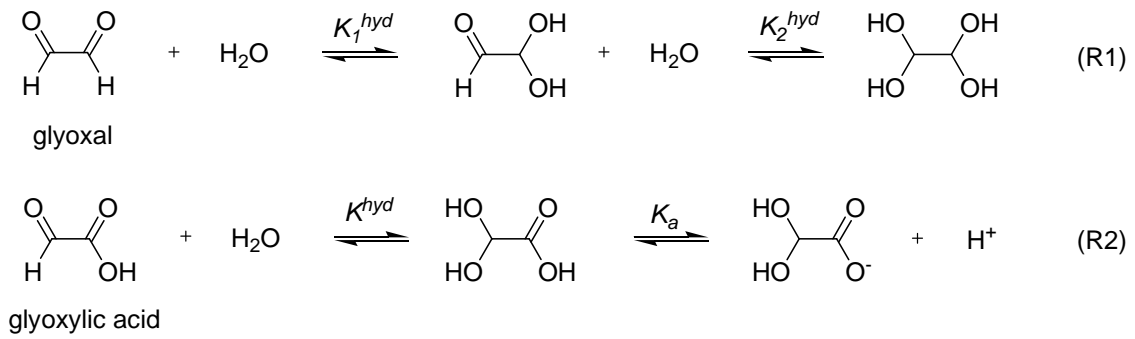

48 The experimentally determined values in this work are the effective Henry's law constants, which include terms for the hydration constants and the acid dissociation constants in the case

50 of carboxylic acids [Betterton and Hoffmann, 1988]. That is, for glyoxal, $K_{\mathrm{H}}=K_{\mathrm{H}}{ }^{\prime}\left(1+K_{1}\right.$ hyd $\left.+K_{1}^{\text {hyd }} K_{2}^{\text {hyd }}\right)$; for glyoxylic acid, $K_{\mathrm{H}}=K_{\mathrm{H}}{ }^{\prime}\left(1+K^{\text {hyd }}+K^{\text {hyd }} K_{\mathrm{a}} /\left[\mathrm{H}^{+}\right]\right)$; and for glycolic acid,

$52 K_{\mathrm{H}}=K_{\mathrm{H}}{ }^{\prime}\left(1+K_{\mathrm{a}} /\left[\mathrm{H}^{+}\right]\right)$, where $K_{\mathrm{H}}$ ' is the intrinsic Henry's law constant. The intrinsic Henry's law constant can be calculated from the effective Henry's law constant for 54 compounds with known hydration and acid dissociation constants.

\section{Experimental Section}

$56 \quad 2.1$ Materials

Glyoxal trimer dihydrate (Sigma), glycolic acid (Acros), glyoxylic acid (Acros), 2,458 dinitrophenylhydrazine (DNPH) (Sigma) were used as received. A glyoxal solution of $\sim 5$ $\mathrm{mM}$ was prepared by dissolving glyoxal trimer dihydrate in water and the solution was

60 allowed to sit in the dark overnight to ensure complete hydrolysis. The glyoxal solution at such a concentration level contained only monomers [Whipple, 1970].

\section{$62 \quad 2.2$ Methods}

A bubble-column technique was used to measure $K_{\mathrm{H}}$. The apparatus, shown schematically 64 in Figure 1, was modified from the design by Mackay et al. [1979] and Betterton and Hoffmann [1988]. It consisted of a conditioning column, a stripped column and an absorbing column of the same dimensions (70 $\mathrm{cm}$ long and $4 \mathrm{~cm}$ i.d.), all placed in a temperaturecontrolled water bath. The columns were connected using silicone rubber tubing. A heating tape was used to maintain the tubing connection at least $5^{\circ} \mathrm{C}$ above the operating temperature 
of the water bath to prevent condensation. Glass-wool plugs were inserted to eliminate mist carry-over. The gas exiting the stripped column was collected by an absorbing solution. In a typical experiment, ultra pure nitrogen gas passed through the first column containing $1 \mathrm{~L}$ of water (at a liquid depth of $64 \mathrm{~cm}$ ) where it was conditioned to the required temperature and humidity. The conditioned gas was then bubbled through the stripped column containing $1 \mathrm{~L}$ of $5 \mathrm{mM}$ solution of the target compound at a flow rate of $250 \mathrm{~mL} \mathrm{~min}^{-1}$. All solutions were prepared within three days prior to each experiment. The system was equilibrated at a specific temperature for $12 \mathrm{~h}$ before sample collection for $K_{\mathrm{H}}$ measurements at this temperature. The experiment at each temperature was repeated three times or more. phase to the gas phase in a bubble column is described by the following equation:

$$
\ln \left(\frac{C_{t}}{C_{o}}\right)=-\left(\frac{G}{K_{H} V R T}\right) t
$$

where $G$ is the gas flow rate $\left(\mathrm{L} \min ^{-1}\right), V$ is the volume of the liquid (L) in the stripped

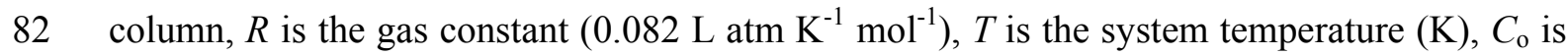
the initial solute concentration and $C_{\mathrm{t}}$ is the solute concentration after time $t(\mathrm{~min})$ in the stripped column. A plot of $\ln \left(C_{\mathrm{t}} / C_{\mathrm{o}}\right)$ against time yields a linear correlation with a slope of $\left(-G /\left(K_{\mathrm{H}} V R T\right)\right)$, from which $K_{\mathrm{H}}$ can be calculated. $C_{t}$ in the stripped column was computed to

86 be $C_{\mathrm{o}}-C_{\mathrm{a}}$, where $C_{\mathrm{a}}$ is the concentration in the absorbing column. $C_{\mathrm{a}}$ was monitored by removing aliquots of the absorbing solution at different time intervals for chemical analysis.

88 Five or more samples were taken in each experiment at a given temperature. The sampling time interval between two consecutive samples was $30 \mathrm{~min}$ for glyoxylic acid and glycolic acid and varied from 1 to $6 \mathrm{~h}$ for glyoxal. An aliquot of $1 \mathrm{~mL}$ was withdrawn for glyoxylic acid and glycolic acid while an aliquot of 10-20 mL was removed for glyoxal. The higher $K_{\mathrm{H}}$

92 values for glyoxal required longer sampling intervals and larger aliquots of solution for analysis. $C_{\mathrm{a}}$ was corrected to the volume of the stripped column. Glycolic acid and glyoxylic 
94 acid were analyzed using ion chromatography (IC) with $5 \mathrm{mM} \mathrm{NaOH}$ as eluent. Glyoxal was quantified in its DNPH derivative using High-Performance Liquid Chromatography with detection of light absorption at $420 \mathrm{~nm}$.

\section{Results and Discussion}

\subsection{Validation of the bubble column technique}

The set-up was first optimized and validated by measuring the $K_{\mathrm{H}}$ of acetic acid and formaldehyde. Their experimental $K_{\mathrm{H}}$ values are known from previous studies. In the bubble column technique to obtain $K_{\mathrm{H}}$, the solute in the exit vapor must be in equilibrium with the liquid. The lower $K_{\mathrm{H}}$ a compound has, the longer it takes to attain the gas-liquid equilibrium

104 [Mackay et al., 1979]. Formaldehyde and acetic acid, having a lower $K_{\mathrm{H}}$ than the three target compounds, require more stringent conditions (e.g., lower flow rate, higher liquid depth) to

106 attain the gas-liquid equilibrium. A few studies measured the effective $K_{\mathrm{H}}$ of formaldehyde at $298 \mathrm{~K}$, reporting values of $3.0 \times 10^{3} \mathrm{M} \mathrm{atm}^{-1}$ [Betterton and Hoffmann, 1988], 3.1 $\times 10^{3} \mathrm{M} \mathrm{atm}^{-1}$

108 in a seawater matrix [Zhou and Mopper, 1990], and 6.0 $\times 10^{3} \mathrm{M} \mathrm{atm}^{-1}$ [Gaffney and Senum, 1984]. We measured formaldehyde $K_{\mathrm{H}}$ to be $4.8 \times 10^{3} \mathrm{M} \mathrm{atm}^{-1}$, falling within the range of

110 these reported values. Three studies reported the $K_{\mathrm{H}}$ value of acetic acid at $298 \mathrm{~K}$. They were $4.1 \times 10^{3} \mathrm{M} \mathrm{atm}^{-1}$ by Johnson et al. [1996], $5.5 \times 10^{3} \mathrm{M}^{-1} \mathrm{~atm}^{-1}$ by Khan et al. [1995], and

$1129.3 \times 10^{3} \mathrm{M} \mathrm{atm}^{-1}$ by Servant et al. [1991]. Our measurement of acetic acid $K_{\mathrm{H}}$ was $5.0 \times 10^{3} \mathrm{M}$ $\mathrm{atm}^{-1}$, also in the range of the published measurements. The measurement results for the $K_{\mathrm{H}}$

114 of formaldehyde and acetic acid have demonstrated that the flow rate in the range of 200-300 $\mathrm{mL} \min ^{-1}$ and the liquid depth $(64 \mathrm{~cm})$ used in this work was adequate to ensure liquid-gas 116 equilibrium.

\subsection{The Henry's law constant of glyoxal}

118 Measurements of the glyoxal $K_{\mathrm{H}}$ were made at four temperatures and the results are listed in Table 1. A plot of the $K_{\mathrm{H}}$ measurements as a function of $1 / T$ yields a solution 
120 enthalpy of $-62.2 \mathrm{~kJ} \mathrm{~mol}^{-1}$. The measured glyoxal $K_{\mathrm{H}}$ at $298 \mathrm{~K}$ was $4.2 \times 10^{5} \mathrm{M} \mathrm{atm}^{-1}$, in good agreement with the value of $3.6 \times 10^{5} \mathrm{M} \mathrm{atm}^{-1}$ in the seawater matrix measured by Zhou and 122 Mopper [1990] and consistent with the lower limit value of $3.0 \times 10^{5} \mathrm{M} \mathrm{atm}^{-1}$ reported by Betterton and Hoffmann [1988] based on their analytical detection limit $(\sim 5 \mu \mathrm{M})$ for 124 aqueous-phase glyoxal.

Recently, Kroll et al. [2005] measured the effective glyoxal $K_{\mathrm{H}}$ to be $2.6 \times 10^{7} \mathrm{M} \mathrm{atm}^{-1}$

126 in a chamber study. This value was obtained from partition of glyoxal between gas phase and ammonium sulfate seed particles or mixed ammonium sulfate/sulfuric acid seed particles.

128 The partition of glyoxal onto the two types of seed particles was found to yield the same effective Henry's law constant. On the basis of this observation, Kroll et al. suggested that 130 the high ionic strength $(19.5-22.5 \mathrm{M})$ in the aerosol aqueous phase was responsible for the enhanced $K_{\mathrm{H}}$ in comparison with the $K_{\mathrm{H}}$ measured in the seawater matrix by Zhou and 132 Mopper.

We measured $K_{\mathrm{H}}$ of glyoxal in $\mathrm{NaCl}$ and $\mathrm{Na}_{2} \mathrm{SO}_{4}$ solutions to investigate the effect of 134 ionic strength. A series of experiments were conducted in $\mathrm{NaCl}$ solutions of different ionic strength ranging from 0.05 to $4.0 \mathrm{M}$. The measured $K_{\mathrm{H}}$ was $1.90 \times 10^{6} \mathrm{M}$ atm $^{-1}$ at an ionic 136 strength of $0.05 \mathrm{M}$ and dropped by $\sim 50 \%$ to $8.50 \times 10^{5} \mathrm{M}$ atm $^{-1}$ when the ionic strength increased to 4.0 M. The $K_{\mathrm{H}}$ value measured in the highest ionic strength $\mathrm{NaCl}$ solution was

138 twice that measured in pure water. The enhancement of $K_{\mathrm{H}}$ was possibly facilitated by the weak hydrogen bonding formed between $\mathrm{Cl}^{-}$ion and the $-\mathrm{OH}$ groups in the hydrated form of 140 glyoxal [Wan and $\mathrm{Yu}, 2007$ ]. Further increase in the $\mathrm{NaCl}$ concentration lowered the $K_{\mathrm{H}}$. It was likely a result of shift in the hydration equilibrium in favor of the aldehyde form since $\mathrm{Cl}^{-}$ 142 and $\mathrm{Na}^{+}$ions compete for water molecules to form hydration shells [Schartzenbach et al., 2003], leading to more prominent salt-out effect with increasing $\mathrm{NaCl}$ concentration.

144 In the experiments carried out in $\mathrm{Na}_{2} \mathrm{SO}_{4}$ solutions, the ionic strength varied from 0.0003 to $0.03 \mathrm{M}$ while the concentration of glyoxal was fixed at $10 \mathrm{mM}$. The corresponding 
146 sulfate:glyoxal molar ratio ranged from $0.01: 1$ to $1: 1 . K_{\mathrm{H}}$ was found to increase significantly with increasing $\mathrm{SO}_{4}{ }^{2-}$ concentration and reached a value of $2.40 \times 10^{7} \mathrm{M} \mathrm{atm}^{-1}$ in the solution

148 having the highest ionic strength $(0.03 \mathrm{M})$. This value was similar to the $K_{\mathrm{H}}$ value derived by Kroll et al. in their chamber study, but it was $\sim 50$ times higher than the $K_{\mathrm{H}}$ measured in pure

150 water and 12 times higher than the $K_{\mathrm{H}}$ measured in the $\mathrm{NaCl}$ solution at an ionic strength of $0.05 \mathrm{M}$. More experiments were conducted, in which the $\mathrm{SO}_{4}{ }^{2-}$ concentration was further 152 increased to $0.15 \mathrm{M}$ (ionic strength $0.225 \mathrm{M}$, and sulfate:glyoxal $=15: 1$ ) to make the sulfate:glyoxal ratio closer to those observed in ambient clouds and aerosols. It was found

154 that the resulting effective $K_{\mathrm{H}}$ was too high $\left(>10^{9} \mathrm{M} \mathrm{atm}^{-1}\right)$ for measurement by our method, since a 6-h collection time was not long enough to obtain sufficient glyoxal in the absorbing 156 column for analysis. Our measurement results pointed to that sulfate was a more important factor than the ionic strength in affecting the glyoxal $K_{\mathrm{H}}$. We have yet to understand the 158 reactive interaction of sulfate ions with the hydrated glyoxal forms.

\subsection{The Henry's law constants of glyoxylic and glycolic acid}

160 The measured $K_{\mathrm{H}}$ values of glyoxylic and glycolic acid at four temperatures are given in Table 1. The solution $\mathrm{pH}$ was not controlled in the experiments. Consequently, the 162 concentrations of the acids and their respective acid dissociation constants determined the resulting solution $\mathrm{pH}$ (Table 1). Plots of $-\ln K_{\mathrm{H}}$ versus $1 / T$ yielded $\Delta \mathrm{H}$ values of -33.5 and -

$16440.0 \mathrm{~kJ} \mathrm{~mol}^{-1}$ for glycolic acid and glyoxylic acid, respectively. Our measured $\Delta \mathrm{H}$ for glycolic and glyoxylic acids are in good agreement with $\Delta \mathrm{H}$ values for the other carboxylic 166 acids. Khan et al. [1995] reported $\Delta \mathrm{H}$ values of pyruvic, pentanoic, and hexanoic acid as $42.3,-54.7$, and $-52.4 \mathrm{~kJ} \mathrm{~mol}^{-1}$, respectively.

$168 \quad 3.4$ Atmospheric Implications

The knowledge of $K_{\mathrm{H}}$ makes it possible to assess the phase distribution, which in turn

170 is a necessary step in evaluating the fate of glyoxal, glycolic acid and glyoxylic acid and their potential contributions to secondary organic aerosol. The partitioning of atmospheric species 
172 into cloud droplets involves multiple steps and the key step is transport across the interface [Schwartz, 1986]. The characteristic time to achieve interfacial equilibrium is strongly 174 dependent on the Henry's law constant and can be calculated with the knowledge of $K_{\mathrm{H}}$ and the accommodation coefficient of a species using the following equation [Betterton, 1992;

176 Schwartz, 1986]:

$$
\tau_{\mathrm{H}}=\left[\left(r^{2} /\left(3 D_{\mathrm{g}}\right)+4 r /(3 \alpha v)\right] R_{\mathrm{g}} T K_{\mathrm{H}}\right.
$$

178 where $r$ is the radius of cloud droplet, $D_{\mathrm{g}}$ is the gas phase diffusion coefficient, $\alpha$ is the mass accommodation coefficient, and $v=\left(8 R_{\mathrm{g}} T / \pi M\right)^{1 / 2}$ is the mean thermal velocity of molecules 180 in the gas phase ( $\mathrm{M}$ is the molecular weight). Schweitzer et al. [1998] reported an average accommodation coefficient of glyoxal by water droplets to be 0.023 in the temperature range

182 of 263-283 K. If we assume an accommodation coefficient of 0.01 (a lower value typically employed in cloud physics computation [Schwartz, 1986]), a cloud droplet radius of $5.0 \mu \mathrm{m}$

184 and a temperature of $288 \mathrm{~K}$, the characteristic times required to achieve gas-droplet equilibrium are $54 \mathrm{~s}$ for glyoxal, $4 \mathrm{~s}$ for glycolic acid $(\mathrm{pH}=3)$, and $1.6 \mathrm{~s}$ for glyoxylic acid

$186(\mathrm{pH}=3)$. The calculations indicate that the gas-droplet equilibrium could be readily established under atmospheric conditions.

188 Using the $K_{\mathrm{H}}$ values measured in pure water, we calculate that with the typical liquid water content of clouds of $0.1-1 \mathrm{~g} \mathrm{~m}^{-3}$ (i.e., $10^{-7}-10^{-6} \mathrm{v} / \mathrm{v}$ ), $78-97 \%$ of glyoxal, $17-67 \%$ of 190 glycolic acid, and 6-38\% of glyoxylic acid partition into the cloud water at equilibrium at $5^{\circ} \mathrm{C}$ (Figure 2). In other words, glyoxal predominately resides in clouds at equilibrium while a 192 smaller but still significant fraction of glycolic acid and glyoxylic acid is in clouds at equilibrium. The significant partitioning of glyoxal in cloud water predicted by its Henry's

194 law constant is confirmed by field measurements. Munger et al. [1995] observed that up to $50 \%$ of glyoxal was partitioned in the aqueous phase during cloudy periods encountered in 196 the Shenandoah National Park, USA during September 1990. Glyoxal in cloud/fog water was also detected in Riverside, California, USA [Munger et al., 1990]. 

predict that in wet aerosols (typical liquid water content in the range of $1-100 \mu \mathrm{g} \mathrm{m}^{-3}$ ), the fractions of glyoxal, glycolic acid, and glyoxylic acid in particle phase are negligible (Figure 2). The effective glyoxal Henry's law constant in pure water is apparently not high enough to 202 explain its observed presence in particle phase. Matsunaga et al. [2004] measured gasparticle partitioning of glyoxal in a forest atmosphere in Japan in August 2002 and reported

204 that the fraction of glyoxal residing in the particle phase ranged from zero to $100 \%$ and average at $46 \%$.

206 In addition to liquid water content, atmospheric factors such as other constituents in cloud water/aerosols, acidity, and ionic strength could significantly affect the partitioning of

208 glyoxal, as demonstrated by the observed higher $K_{\mathrm{H}}$ values in the presence of $\mathrm{NaCl}$ and $\mathrm{Na}_{2} \mathrm{SO}_{4}$ in this work. Volkamer et al. [2007] compared direct measurements of gas-phase

210 glyoxal in Mexico City to experimentally constrained model prediction and concluded that there must be an additional glyoxal sink. They suggested reversible partitioning to aerosol

212 liquid water with a $K_{\mathrm{H}}$ as high as $4 \times 10^{9} \mathrm{M} \mathrm{atm}^{-1}$ to be a possible sink to account for the discrepancy between the model prediction and the measurements. Certain strong interactions

214 between glyoxal with other aerosol constituents have to be involved to account for the high effective $K_{\mathrm{H}}$ suggested by Volkamer et al., since this suggested $K_{\mathrm{H}}$ value is four orders of

216 magnitude higher than the $K_{\mathrm{H}}$ in pure water. Such a high $K_{\mathrm{H}}$ is possible and in general agreement with our lower-limit estimate for $K_{\mathrm{H}}$ in the presence of $0.15 \mathrm{M}$ sulfate and $10 \mathrm{mM}$

218 glyoxal. It is apparent that further work is needed to quantify the effects of sulfate, acidity, and ionic strength on partitioning of glyoxal between the gas and aqueous phases.

\section{Acknowledgement}

222 This work was supported by the Research Grant Council of Hong Kong, China (621806 and 621708). 
Betterton, E. A. (1992), Henry's law constants of soluble and moderately soluble organic 226 gases: effects of aqueous phase chemistry, Adv. Env. Sci. Technol., 24, 1-50.

Betterton, E. A., and M. R. Hoffmann (1988), Henry's law constants of some environmentally

228 important aldehydes, Environ. Sci. Technol., 22, 1415-1418.

Blando, J. D., and B. J. Turpin (2000), Secondary organic aerosol formation in cloud and fog

230 droplets: A literature evaluation of plausibility, Atmos. Environ., 34, 1623-1632.

Gaffney, J. S., and G. I. Senum (1984), In L. Newman, editor, Gas-Liquid Chemistry of

232 Natural Waters, NTIS TIC-4500, UC-4511, BNL 51757 Brookhaven National Laboratory, 5$1-5-7$.

234 Ho, S. S. H., and J. Z. Yu (2002), Feasibility of collection and analysis of airborne carbonyls by on-sorbent derivatization and thermal desorption, Anal. Chem., 74, 1232-1240.

236 Johnson, B. J., E. A. Betterton, and D. Craig (1996), Henry's Law coefficients of formic and acetic acids, J. Atmos. Chem., 24, 113-119.

238 Khan, I., P. Brimblecombe, and S. L. Clegg (1995), Solubilities of pyruvic acid and the lower (C1-C6) carboxylic acids. Experimental determination of equilibrium vapour pressures above 240 pure aqueous and salt solutions, J. Atmos. Chem., 22, 285-302.

Kroll, J. H., N. L. Ng, S. M. Murphy, V. Varutbangkul, R. C. Flagan, and J. H. Seinfeld

242 (2005), Chamber studies of secondary organic aerosol growth by reactive uptake of simple carbonyl compounds, J. Geophys. Res., 110, 1-10.

244 Mackay, D., W. Y. Shiu, and R. P. Sutherland (1979), Determination of air-water Henry's law constants for hydrophobic pollutants, Environ. Sci. Technol., 13, 333-337.

246 Matsunaga, S., M. Mochida, and K. Kawamura (2004), Variation of the atmospheric concentrations of biogenic carbonyl compounds and their removal processes in the northern

248 forest at Moshiri, Hokkaido Island in Japan, J. Geophys. Res., 109, D04302, doi: 10.1029/2003JD004100. 
250 Munger, J. W., J. Collett Jr, B. Daube Jr, and M. R. Hoffmann (1990), Fogwater chemistry at Riverside, California, Atmos. Environ., 24B, 185-205.

252 Munger, J. W., D. J. Jacob, B. C. Danube, L. W. Horowitz, W. C. Keene, and B. G. Heikes (1995), Formaldehyde, glyoxal, and methylglyoxal in air and cloudwater at a rural mountain

254 site in central Virginia, J. Geophys. Res., 100, 9325-9333.

Schwartz, S. E. (1986), Mass-transport considerations pertinent to aqueous phase reactions of

256 gases in liquid-water clouds, Chemistry of Multiphase Atmospheric Systems, 415-471.

Schwarzenbach, R. P., P. M. Gschwend, D. M. Imboden (2003), Environmental Organic

258 Chemistry, John Wiley \& Sons, New Jersey.

Schweitzer, F., L. Magi, P. Mirabel, and C. George (1998), Uptake rate measurements of

260 methanesulfonic acid and glyoxal by aqueous droplets, J. Phys. Chem. A, 102, 593-600.

Servant, J., G. Kouadio, B. Cros, and R. Delmas (1991), Carboxylic monoacids in the air of

262 Mayombe forest (Congo): Role of the forest as a source or sink, J. Atmos. Chem., 12, 367380.

264 Smith, R. M., and A. E. Martell (1977), Critical Stability Constants, 3. Other Organic Ligands, Plenum Press, London.

266 Sorooshian, A., V. Varutbangkul, F. J. Brechtel, B. Ervens, G. Feingold, R. Bahreini, S. M. Murphy, J. S. Holloway, E. L. Atlas, G. Buzorius, H. Jonsson, R. C. Flagan, and J. H.

268 Seinfeld (2006), Oxalic acid in clear and cloudy atmospheres: Analysis of data from International Consortium for Atmospheric Research on Transport and Transformation 2004, J.

270 Geophys. Res., 111, D23S45, doi:10.1029/2005JD006880.

Sørensen, P. E., K. Bruhn, and F. Lindeløv (1974), Kinetics and equilibria for the reversible

272 hydration of the aldehyde group on glyoxylic acid, Acta Chem. Scand., A28, 162-168.

Vel Leitner, N. K. and M. Dore (1997), Mechanism of the reaction between hydroxyl radicals

274 and glycolic, glyoxylic, acetic and oxalic acids in aqueous solution: Consequence on 
hydrogen peroxide consumption in the $\mathrm{H}_{2} \mathrm{O}_{2} / \mathrm{UV}$ and $\mathrm{O}_{3} / \mathrm{H}_{2} \mathrm{O}_{2}$ systems, Wat. Res., 31, 13832761397.

Volkamer, R., L. T. Molina, M. J. Molina, T. Shirley, and W. H. Brune (2005), DOAS

278 measurement of glyoxal as an indicator for fast VOC chemistry in urban air, Geophys. Res. Lett., 32, 1-4.

280 Volkamer, R., F. SanMartini, L. T. Molina, D. Salcedo, J. Jimenez, and M. J. Molina (2007), A missing sink for gas-phase glyoxal in Mexiko City: Formation of secondary organic 282 aerosol, Geophys. Res. Lett., 34, L19807, doi: 10.1029/2007GL030752.

Wan, E. C. H., and J. Z. Yu (2007), Analysis of sugars and sugar polyols in atmospheric 284 aerosols by chloride attachment in liquid chromatography/negative ion slectrospray mass spectrometry, Environ. Sci. Technol., 41, 2459-2466.

286 Warneck, P. (2003), In-cloud chemistry opens pathway to the formation of oxalic acid in the marine atmosphere, Atmos. Environ., 37, 2423-2427.

288 Wasa, T., and Musha, S. (1970), Polarographic behavior of glyoxal and its related compounds, Univ. Osaka Prefect Ser. A, 19, 169-180.

290 Whipple, E. B. (1970), The structure of glyoxal in water, J. Am. Chem. Soc., 92, 7183-7186. Yu, J. Z., X. F. Huang, J. Xu, and M. Hu (2005), When aerosol sulfate goes up, so does 292 oxalate: Implication for the formation mechanisms of oxalate, Environ. Sci. Technol., 39, 128-133.

294 Zhou, X., and K. Mopper (1990), Apparent partition coefficients of 15 carbonyl compounds between air and seawater and between air and freshwater; implications for air-sea exchange, 296 Environ. Sci. Technol., 24, 1864-1869. 
Table 1. Summary of Effective Henry's law constants for glyoxal, glyoxylic and glycolic acid

\begin{tabular}{|c|c|c|c|c|c|}
\hline Aldehyde & $\begin{array}{l}\text { Temp. } \\
\text { (K) }\end{array}$ & $\begin{array}{c}K_{\mathrm{H}} \\
\left(\mathrm{M} \mathrm{atm}^{-1}\right)\end{array}$ & $\mathrm{pH}$ & $\begin{array}{l}K_{\mathrm{H}, \text { intrinsic }} \\
\left.(\mathrm{M} \mathrm{atm})^{-1}\right)\end{array}$ & Reference \\
\hline \multirow[t]{6}{*}{ Glyoxal } & 298 & $3.6 \times 10^{5}$ & & & Zhou and Mopper [1990] \\
\hline & $\begin{array}{c}288,298, \\
308,318\end{array}$ & $\geq 3.00 \times 10^{5}$ & & & Betterton and Hoffmann [1988] \\
\hline & 278 & $(1.60 \pm 0.11) \times 10^{6}$ & 7 & & This work $^{\mathrm{d}}$ \\
\hline & 298 & $(4.19 \pm 0.87) \times 10^{5}$ & 7 & $1.90^{\mathrm{a}}$ & This work $^{\mathrm{d}}$ \\
\hline & 308 & $(1.53 \pm 0.16) \times 10^{5}$ & 7 & & This work $^{\mathrm{d}}$ \\
\hline & 318 & $(4.97 \pm 0.30) \times 10^{4}$ & 7 & & This work $^{\mathrm{d}}$ \\
\hline \multirow[t]{4}{*}{ Glyoxylic acid } & 278 & $(2.72 \pm 0.53) \times 10^{4}$ & 2.76 & & This work $^{\mathrm{d}}$ \\
\hline & 288 & $(1.90 \pm 0.21) \times 10^{4}$ & 2.64 & & This work $^{\mathrm{d}}$ \\
\hline & 298 & $(1.09 \pm 0.09) \times 10^{4}$ & 2.64 & $28.67^{b}$ & This work $^{\mathrm{d}}$ \\
\hline & 308 & $(4.97 \pm 0.51) \times 10^{3}$ & 2.84 & & This work $^{\mathrm{d}}$ \\
\hline \multirow[t]{4}{*}{ Glycolic acid } & 278 & $(8.95 \pm 0.75) \times 10^{4}$ & 3.09 & & This work $^{\mathrm{d}}$ \\
\hline & 288 & $(4.82 \pm 0.47) \times 10^{4}$ & 3.11 & & This work $^{\mathrm{d}}$ \\
\hline & 298 & $(2.83 \pm 0.31) \times 10^{4}$ & 3.12 & $2.37 \times 10^{4 \mathrm{c}}$ & This work $^{\mathrm{d}}$ \\
\hline & 308 & $(2.24 \pm 0.29) \times 10^{4}$ & 2.95 & & This work $^{\mathrm{d}}$ \\
\hline
\end{tabular}

${ }^{a}$ The intrinsic $K_{\mathrm{H}}$ at $298 \mathrm{~K}$ for glyoxal was calculated from its effective $K_{\mathrm{H}}$ using a hydration constant of $2.2 \times 10^{5} \mathrm{M}$ measured by Wasa and Musha [1970].

${ }^{\mathrm{b}}$ The intrinsic $K_{\mathrm{H}}$ at $298 \mathrm{~K}$ for glyoxylic acid was calculated from its effective $K_{\mathrm{H}}$ using a hydration constant of 3.0x10 ${ }^{2} \mathrm{M}$ [Sørensen et al., 1974] and an acid dissociation of $3.47 \times 10^{-4} \mathrm{M}$ for the hydrated form of glyoxylic acid [Smith and Martell., 1977].

${ }^{\mathrm{c}}$ The intrinsic $K_{\mathrm{H}}$ at $298 \mathrm{~K}$ for glycolic acid was calculated from its effective $K_{\mathrm{H}}$ using an acid dissociation of $1.58 \times 10^{-4} \mathrm{M}$ [vel Leitner and Dore, 1997].

${ }^{\mathrm{d}}$ The $K_{\mathrm{H}}$ values as a function of temperature in the form of $\mathrm{K}_{\mathrm{H}}=\mathrm{K}_{\mathrm{H}, 298 \mathrm{~K}} \times \exp \left[\frac{-\Delta \mathrm{H}}{\mathrm{R}} \times\left(\frac{1}{\mathrm{~T}}-\frac{1}{298}\right)\right]$ derived from measurements at different temperatures in this work are:

Glyoxal: $\mathrm{K}_{\mathrm{H}}=4.19 \times 10^{5} \times \exp \left[\frac{62.2 \times 10^{3}}{\mathrm{R}} \times\left(\frac{1}{\mathrm{~T}}-\frac{1}{298}\right)\right]$; glycolic acid: $\mathrm{K}_{\mathrm{H}}=2.83 \times 10^{4} \times \exp \left[\frac{33.5 \times 10^{3}}{\mathrm{R}} \times\left(\frac{1}{\mathrm{~T}}-\frac{1}{298}\right)\right]$; and glyoxylic acid: $\mathrm{K}_{\mathrm{H}}=1.09 \times 10^{4} \times \exp \left[\frac{40.0 \times 10^{3}}{\mathrm{R}} \times\left(\frac{1}{\mathrm{~T}}-\frac{1}{298}\right)\right]$. 


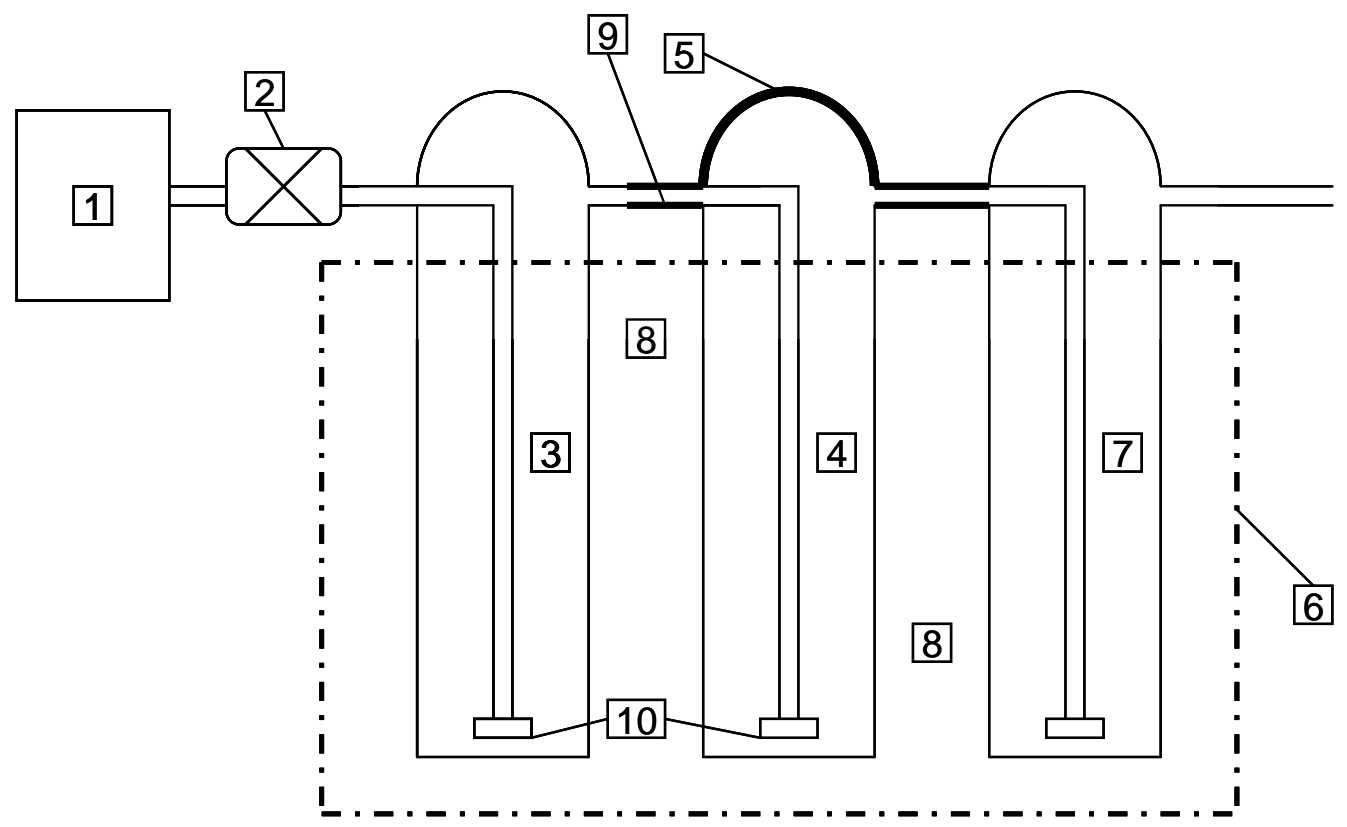

Figure 1.Schematic diagram of the bubble-column setup. (1) Nitrogen carrier gas tank, (2) Flow meter, (3) Conditioning column containing pure water, (4) Stripped column solution containing the target compound, (5) Heating tape, (6) Water bath, (7) 1L of pure water to collect sample, (8) Thermometer, (9) Glass wool, and (10) Stainless steel slip-on inlet filters with porosity of $10 \mu \mathrm{m}$ 


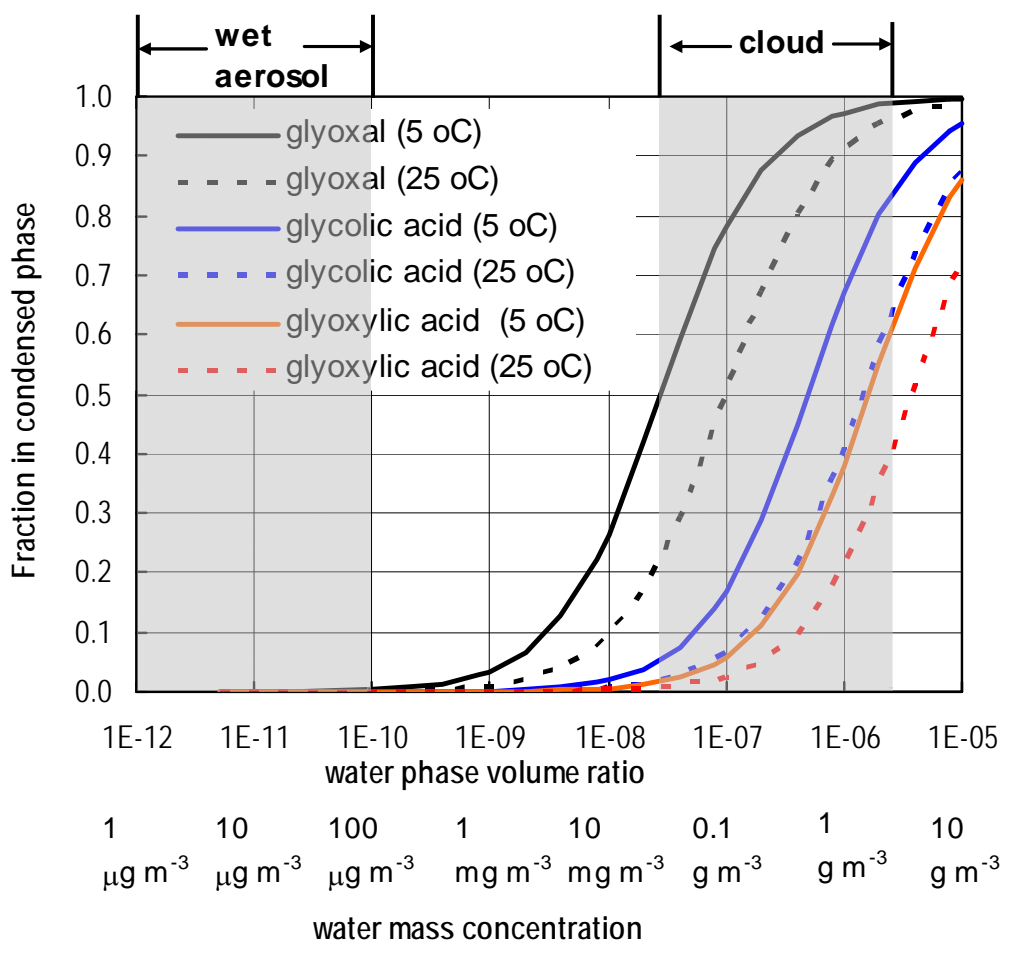

Figure 2. Calculated fractions of glyoxal, glycolic acid, and glyoxylic acid in cloud water and in wet aerosols as a function of water phase volume ratio, assuming Henry's Law Constant (HLC) values measured in pure water. (The shaded areas indicate the typical range of liquid water content for wet aerosols (1-100 $\left.\mu \mathrm{g} \mathrm{m}^{-3}\right)$ and for clouds $\left(0.05-3 \mathrm{~g} \mathrm{~m}^{-3}\right)$ ). 